\title{
Epithelial PIK3R1 (p85) and TP53 Regulate Survivin Expression during Adaptation to Ileocecal Resection
}

Valeria Cohran, * Elizabeth Managlia, ${ }^{*}$ Emily M. Bradford, ${ }^{\dagger}$ Tatiana Goretsky, ${ }^{\dagger}$ Ting Li, ${ }^{\ddagger}$ Rebecca B. Katzman, ${ }^{\S}$ Paul Cheresh, ${ }^{\S}$ Jeffrey B. Brown, * Jennifer Hawkins, "Shirley X.L. Liu, ${ }^{*}$ Isabelle G. De Plaen, ${ }^{*}$ Jörn-Hendrik Weitkamp, Michael Helmrath, Zheng Zhang, ${ }^{\ddagger}$ and Terrence A. Barrett ${ }^{\dagger \S}$

From the Department of Pediatrics, * Ann and Robert H. Lurie Children's Hospital of Chicago, Chicago, Illinois; the Division of Gastroenterology, ${ }^{\dagger}$ Department of Internal Medicine, University of Kentucky, Lexington, Kentucky; the Department of Surgery, ${ }^{\ddagger}$ Comprehensive Transplant Center, and Division of Gastroenterology, ${ }^{\S}$ Department of Medicine, Feinberg School of Medicine, Northwestern University, Chicago, Illinois; the Division of Pediatric General and Thoracic Surgery, "Cincinnati Children's Hospital Medical Center, Cincinnati, Ohio; and the Division of Neonatology," Department of Pediatrics, Vanderbilt University and Monroe Carell Jr. Children's Hospital, Nashville, Tennessee

Accepted for publication

March 2, 2016.

Address correspondence to Terrence A. Barrett, M.D., Division of Gastroenterology, University of Kentucky, 800 Rose St, MN649, Lexington, KY 40536. E-mail: t.barrett@ uky.edu.

\begin{abstract}
Intestinal adaptation to small-bowel resection (SBR) after necrotizing enterocolitis expands absorptive surface areas and promotes enteral autonomy. Survivin increases proliferation and blunts apoptosis. The current study examines survivin in intestinal epithelial cells after ileocecal resection. Wild-type and epithelial Pik3r1 ( $85 \alpha \alpha$ )-deficient mice underwent sham surgery or 30\% resection. RNA and protein were isolated from small bowel to determine levels of $\beta$-catenin target gene expression, activated caspase- 3 , survivin, p85 $\alpha$, and Trp53. Healthy and post-resection human infant small-bowel sections were analyzed for survivin, Ki-67, and TP53 by immunohistochemistry. Five days after ileocecal resection, epithelial levels of survivin increased relative to sham-operated on mice, which correlated with reduced cleaved caspase-3, p85 $\alpha$, and Trp53. At baseline, p85 $\alpha$-deficient intestinal epithelial cells had less Trp53 and more survivin, and relative responses to resection were blunted compared with wild-type. In infant small bowel, survivin in transit amplifying cells increased $71 \%$ after SBR. Resection increased proliferation and decreased numbers of TP53-positive epithelial cells. Data suggest that ileocecal resection reduces p85 $\alpha$, which lowers TP53 activation and releases survivin promoter repression. The subsequent increase in survivin among transit amplifying cells promotes epithelial cell proliferation and lengthens crypts. These findings suggest that SBR reduces $p 85 \alpha$ and TP53, which increases survivin and intestinal epithelial cell expansion during therapeutic adaptation in patients with short bowel syndrome. (Am J Pathol 2016, 186: 1837-1846; http://dx.doi.org/10.1016/j.ajpath.2016.03.008)
\end{abstract}

Intestinal failure from short bowel syndrome (SBS) secondary to intestinal resection leads to significant morbidity and mortality. ${ }^{1}$ Necrotizing enterocolitis (NEC) is a common and often fatal surgical emergency in preterm infants and is the leading cause of SBS in pediatrics. ${ }^{2}$ Increasing survival rates among premature infants has resulted in increased incidence of NEC and SBS. Patients with SBS often require long-term total parenteral nutrition to allow time for the intestine to adapt and compensate for the intestinal loss. ${ }^{3}$ These factors impose a significant burden on the patient and economic challenges for the health care system. ${ }^{4}$

The mammalian intestine is highly proliferative, with intestinal epithelial cell (IEC) turnover occurring every 4 to 5 days. ${ }^{5}$ IEC proliferation is tightly regulated and crucial for rapid repair after intestinal injury or loss. After damage, the remnant bowel compensates for the loss of surface area via a complex process known as intestinal adaptation. Intestinal

\footnotetext{
Supported by NIH grants R01DK-054778 and R01AI-6171702 (T.A.B.), the Eunice Kennedy Shriver National Institute of Child Health and Human Development grant K08HD061607 (J.-H.W.), and the Vanderbilt University Medical Center's Digestive Disease Research Center, supported by NIH grants P30DK058404, R01 HD060876 (I.G.D.P.), K12 HD052902 (V.C.), and DK066161 (J.B.B.). E.M.B. was supported by T32-CA080621 (Richard Carthew, PI). Mouse surgeries were supported by the Microsurgery Core of the Comprehensive Transplant Center at Northwestern University.

V.C., E.M., and E.M.B. contributed equally to this work.

Z.Z. and T.A.B. contributed equally to this work as senior authors.

Disclosures: None declared.
} 
adaptation involves IEC proliferation, villus lengthening, and crypt elongation, which improve fluid and nutritional absorption. The increase in IEC proliferation occurs primarily in the transit amplifying (TA) zone in the midcrypt. $^{5,6}$ This adaptive process can take several years to occur, if ever, and the mechanisms remain poorly understood. $^{3}$ Mouse intestinal resection models that mimic the proliferative aspects of human SBS (ie, villus lengthening and crypt elongation) provide useful tools for exploring mechanisms of post-surgical adaptive processes. ${ }^{7,8}$

Survivin (encoded by the gene BIRC5) is expressed in the progenitor/stem cell zone of the intestinal crypt. Survivin is a Wnt target gene and member of the inhibitor of the apoptosis protein family. ${ }^{9}$ Survivin reduces apoptosis by inhibiting caspase- 3 activation and promotes $\mathrm{G}_{2} / \mathrm{M}$ phase cell cycle progression. ${ }^{9}$ As a Wnt target, survivin transcription is activated by $\beta$-catenin and is repressed by the tumor suppressor TP53. ${ }^{10}$

The TP53 protein is highly regulated by post-translational modification. ${ }^{11}$ Phosphorylation of Ser9 $\left(\mathrm{TP} 53^{\mathrm{Ser} 9}\right.$ ) is important for transcriptional repression of survivin gene expression. ${ }^{12} \mathrm{~N}$-terminal phosphorylation, including Ser9, is also known to enhance TP53 stability by enabling the acetylation of Lys370 (K370) by the coactivator p300/ CBP. ${ }^{12}$ Song et $\mathrm{al}^{13}$ demonstrated that TP53 acetylation is dependent on the phosphoinositide 3-kinase regulatory subunit (PIK3R1) p85 $\alpha$ during the stress response. Acetylated TP53 has a stronger DNA binding capacity and potentially leads to increased transcriptional activity. ${ }^{14}$ Recent observations highlighting the critical role of TP53 in preventing stem cell expansion provide insight into why reductions in TP53 activation post-resection may be mechanistically relevant to adaptive processes. ${ }^{13}$

Using a distal small-bowel resection (SBR) model as opposed to massive SBR, Dekaney et $\mathrm{al}^{7}$ showed significant crypt branching and intestinal epithelial stem cell activation at day 7 after resection. This ileocecal resection (ICR) model closely mimics SBS secondary to NEC, which often affects the distal small bowel and proximal colon. To examine signaling mechanisms before crypt fissioning, we used this model to investigate the IEC responses 5 days after ICR. We found that the $\beta$-catenin target gene survivin is up-regulated 5 days after ICR. Survivin has many functions that are potentially advantageous to the adaptation process: i) it is expressed in the stem/progenitor compartment in the intestinal crypt, ii) it inhibits apoptosis, and iii) it promotes cell cycle progression. In this study, we interrogated the mechanism of survivin induction after ICR because this may play an important role in clinical adaptation to SBS.

\section{Materials and Methods}

Mice and Surgery

C57BL/6J [wild type (WT)], AhCre, and VillinCre mice were purchased from Jackson Laboratory (Bar Harbor, ME).
To delete $\mathrm{p} 85 \alpha$ specifically from epithelial cells, AhCre or VillinCre mice were bred with pik3r $1^{f / f l}$ mice (a gift from Lewis Cantley, Weill Cornell Medical College, New York, $\mathrm{NY}$ ). These are referred to as $p 85^{\Delta I E C}$ mice. For AhCre mice, the cre-recombinase was induced by i.p. injection of $80 \mathrm{mg} / \mathrm{kg}$ of $\beta$-naphthoflavone (Sigma, St. Louis, MO) dissolved in $8 \mathrm{mg} / \mathrm{mL}$ corn oil (Sigma) every day for 6 days. Mice were maintained under specific pathogen-free conditions, and all experiments were approved by the Institutional Animal Care and Use Committee. Sham-resected mice underwent small intestinal transection at the jejunoileal junction, approximately $10 \mathrm{~cm}$ distal to the ligament of Treitz, followed by reanastomosis without resection. Experimental mice underwent ICR, removing both ileum and cecum (approximately 30\%). An end-to-end anastomosis between the remaining small intestine and ascending colon was performed using interrupted 9-0 silk sutures. Mice were provided water and fluid replacement $(2 \mathrm{~mL}$ Ringer's $+5 \%$ dextrose, twice a day) for 60 hours after surgery. To assess proliferative responses, mice were injected i.p. with $1 \mathrm{mg}$ bromodeoxyuridine (BrdU; Sigma) 2 hours before sacrifice.

\section{Human Tissues}

Infant ( $<1$ year) ileum sections were analyzed by immunohistochemistry (IHC) for expression of survivin, Ki-67, and TP53. Three control and six post-resection tissues were analyzed (Table 1). Slides were obtained from the Department of Pediatrics, Ann and Robert H. Lurie Children's Hospital (Chicago, IL); the Department of Pediatrics, Vanderbilt University and Monroe Carell Jr. Children's Hospital (Nashville, TN); and the Division of Pediatric General and Thoracic Surgery, Cincinnati Children's Hospital Medical Center (Cincinnati, OH). All tissue collection was approved by the ethical review boards at each institution.

\section{IHC}

Formalin-fixed, paraffin-embedded sections were stained for BrdU (MPL International, Woburn, MA), Ki-67 (Dako, Glostrup, Denmark), survivin (Novus Biologicals, Littleton, CO), and TP53 (Santa Cruz Biotechnology, Dallas, TX) using standard IHC methods. Tissues were counterstained with hematoxylin (except for TP53 staining). For mouse studies, positive cells and crypt lengths were measured in at least 10 well-oriented crypts in the distal jejunum. For human studies, positive cells were counted in the crypt base (positions 1 to 5 in the hemicrypt), the TA zone (positions 6 to 15), and the upper crypt and villi (position $\geq 16$ ).${ }^{15}$ Slides were imaged on an Olympus BX41 microscope with a mounted Olympus DP71 camera (Olympus, Center Valley, PA).

\section{Epithelial Cell Isolation}

Dissected mouse small intestine was opened lengthwise and incubated at $4{ }^{\circ} \mathrm{C}$ in $\mathrm{Ca}^{2+}$ - and $\mathrm{Mg}^{+}$-free $\mathrm{HBSS}$. The tissue 
Table 1 Patient Characteristics

\begin{tabular}{|c|c|c|c|c|c|c|}
\hline Site & Tissue analyzed & $\begin{array}{l}\text { Age at first } \\
\text { surgery (days) }\end{array}$ & $\begin{array}{l}\text { Age at second } \\
\text { surgery or } \\
\text { harvest (days) }\end{array}$ & $\begin{array}{l}\text { Interval } \\
\text { (days) }\end{array}$ & $\begin{array}{l}\text { Gestation } \\
\text { (weeks) }\end{array}$ & Diagnosis \\
\hline Ileum & Control & 12 & 45 & 33 & 23 & $\begin{array}{l}\text { NEC at day } 6 \text {, Penrose drain at day } \\
12 \text { for perforation }\end{array}$ \\
\hline Ileum & Control & 3 & 76 & 73 & 29 & SIP \\
\hline Ileum & Control & 1 & 42 & 42 & 33 & Gastroschisis and jejunal atresia \\
\hline Ileum & Ostomy repair & 0 & 53 & 53 & Term & Gastroschisis with infarcted bowel \\
\hline Ileum & Ostomy repair & 13 & 88 & 75 & 25 & NEC at day 14 \\
\hline Ileum & 0stomy repair & 1 & 56 & 60 & Term & NEC at day 1 \\
\hline Ileum & Ostomy repair & 180 & 252 & 72 & Term & Intestinal failure \\
\hline
\end{tabular}

Surgical data from three control and six small-bowel resection (SBR; ostomy repair) patients. Control patient samples were from healthy tissue taken before resection. For SBR patients, the time to ostomy repair averaged 65 days. When noted in surgical records, resection length ranged between 2 and $10 \mathrm{~cm}$.

NEC, necrotizing enterocolitis; SIP, spontaneous intestinal perforation.

was then transferred to $\mathrm{Ca}^{2+}$ - and $\mathrm{Mg}^{+}$-free HBSS containing $10 \mathrm{mmol} / \mathrm{L}$ dithiothreitol (Sigma) and $50 \mathrm{nmol} / \mathrm{L}$ calyculin A (Wako, Richmond, VA) and incubated for 30 minutes at $4^{\circ} \mathrm{C}$. After incubation, the tissue was shaken briefly and transferred to a fresh solution of $\mathrm{Ca}^{2+}$ - and $\mathrm{Mg}^{+}-$ free HBSS with $1 \mathrm{mmol} / \mathrm{L}$ EDTA and $50 \mathrm{nmol} / \mathrm{L}$ calyculin A. After incubation at $4^{\circ} \mathrm{C}$ for 1 hour, epithelial cells were shaken vigorously for 10 to 15 minutes. Large pieces of tissue were removed from the tube and discarded, and epithelial cells were harvested by centrifugation at $20 \times g$ for 5 minutes. Supernatant was decanted, and cells were snap frozen in liquid nitrogen.

\section{Protein Fractionation and Western Blotting}

Frozen epithelial cell pellets were thawed on ice and passed through a 27 -gauge needle in ice cold buffer (50 $\mathrm{mmol} / \mathrm{L}$ Tris- $\mathrm{HCl}, \mathrm{pH} 7.4,100 \mathrm{mmol} / \mathrm{L} \mathrm{NaCl}$, and $0.01 \%$ digitonin) containing protease (Pierce, Rockford, IL) and phosphatase inhibitor cocktails (Sigma). Cells were incubated for 5 minutes and centrifuged to obtain the cytosolic fraction. The remaining pellet was suspended in ice-cold buffer containing protease and phosphatase inhibitor cocktails $(50 \mathrm{mmol} / \mathrm{L}$ Tris- $\mathrm{HCl}, \mathrm{pH} \mathrm{7.4,2 \%}$ Triton X-100, and $100 \mathrm{mmol} / \mathrm{L} \mathrm{NaCl}$ ), incubated for 30 minutes, and centrifuged to remove the membrane and organelles. Finally, the nuclear extract was purified by resuspension of the pellet in ice-cold buffer, including protease and phosphatase inhibitor cocktails $(50 \mathrm{mmol} / \mathrm{L}$ Tris- $\mathrm{HCl}, \mathrm{pH} 7.4$, $100 \mathrm{mmol} / \mathrm{L} \mathrm{NaCl}, 0.5 \% \mathrm{n}$-dodecyl- $\beta$-D-maltoside, 2.2 $\mathrm{mmol} / \mathrm{L} \mathrm{MgCl}$, and Benzonase) for 30 minutes at room temperature before centrifugation.

The protein fractions were separated by SDS-PAGE using precast gels (Lonza, Rockland, ME) and transferred to polyvinylidene difluoride membrane (Millipore, Billerica, MA) using a semidry electrotransfer apparatus (Bio-Rad, Hercules, CA). The membranes were blocked with protein-free T20 blocking buffer (Pierce, Rockford, IL) and incubated with primary antibodies specific for $\beta$-catenin (BD Biosciences, San Jose, CA), cleaved caspase-3, total TP53, p-TP53 ${ }^{\text {S9 }}$ (Cell Signaling, Danvers, MA), TATA binding protein (Abcam, Cambridge, MA), acetyl$\mathrm{TP} 3^{\mathrm{K} 370}, \mathrm{p} 85 \alpha$ (Millipore), and $\beta$-actin (Sigma), followed by corresponding anti-mouse or anti-rabbit secondary antibodies. Proteins were detected by chemiluminescence (West Pico or West Dura kits; Pierce). Western blots were performed on protein isolated from at least three independent experiments.

\section{Real-Time PCR (Quantitative RT-PCR)}

Tissue was preserved in RNALater (Qiagen, Valencia, CA) before RNA extraction using the RNeasy Mini Kit (Qiagen). Reverse transcription was performed using the cDNA

Table 2 Quantitative RT-PCR Primer Sequences

\begin{tabular}{lll}
\hline Gene & Sequence \\
\hline Gapdh & F & $5^{\prime}$-GAACGGATTTGGCCGTATTG-3' \\
& R & $5^{\prime}$-TGAGTGGAGTCATACTGGAACATGT-3' \\
Lgr5 & F & $5^{\prime}$-CAAACTTCCCAGAGCTCAAGATTAT-3' \\
& R & $5^{\prime}$-TGTTGCCGTCGTCTTATTCC-3' \\
c-Myc & F & $5^{\prime}$-CCACCAGCAGCGACTCTGA-3' \\
& R & $5^{\prime}$-TCCACAGACACCACATCAATTTC-3' \\
Cd44 & F & $5^{\prime}$-AGCAGCGGCTCCACCATCGAGA-3' \\
& R & $5^{\prime}$-TCGGATCCATGAGTCACAGTG-3' \\
Axin2 & F & $5^{\prime}$-CGCCAACGACAGCGAGTTAT-3' \\
& R & $5^{\prime}$-CCATCTACGCTACTGTCCGTCAT-3' \\
Birc5 (survivin) & F & $5^{\prime}$-ATCGCCACCTTCAAGAACTG-3' \\
& R & $5^{\prime}$-GGCCAAATCAGGCTCGTTCT-3' \\
Dr5 & F & $5^{\prime}$-CGGGCAGATCACTACACCC-3' \\
& R & $5^{\prime}$-TGTTACTGGAACAAAGACAGCC-3' \\
Bbc3 (puma) & F & $5^{\prime}$-ATGGCGGACGACCTCAAC-3' \\
& R & $5^{\prime}$-AGTCCCATGAAGAGATTGTACATGAC-3'
\end{tabular}

$F$, forward; R, reverse. 

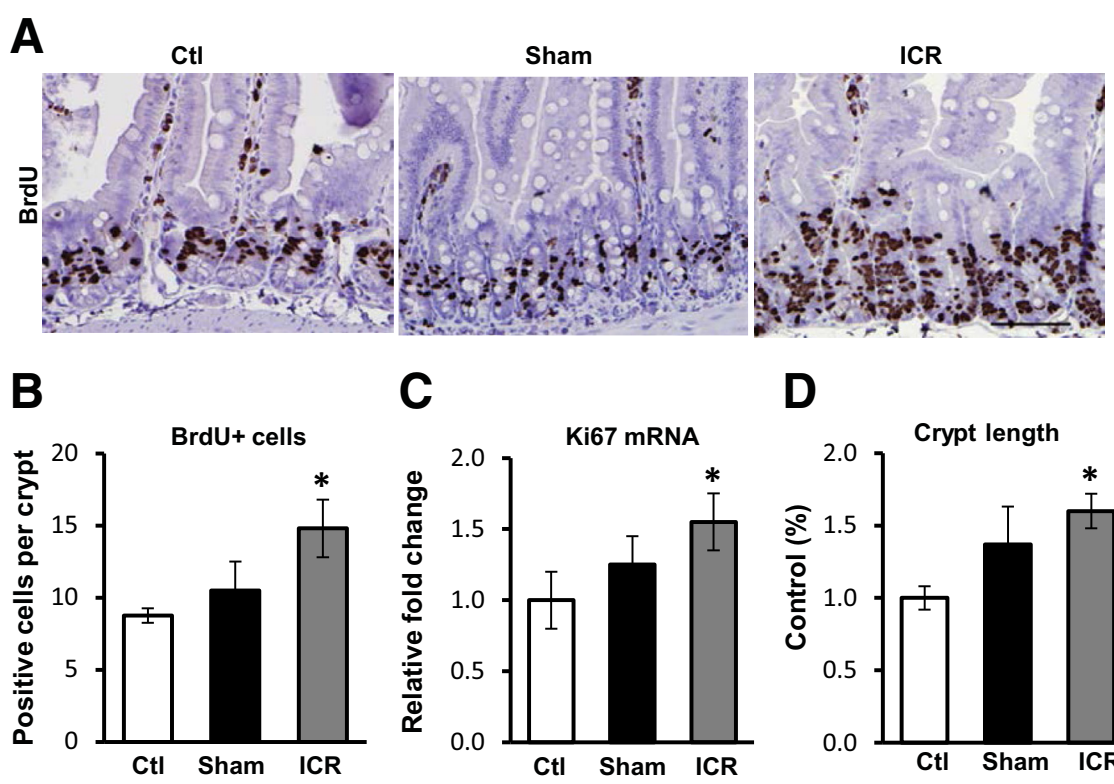

D

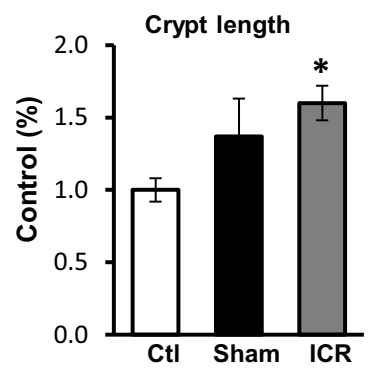

Figure 1 Ileocecal resection (ICR) induces crypt intestinal epithelial cell proliferation and elongation 5 days after surgery. A: Representative immunohistochemistry from control (ctl), sham, and ICR surgery showing increased bromodeoxyuridine (BrdU) incorporation after ICR in mice. B: Quantitation of BrdU-positive cells. C: Realtime RT-PCR for the proliferation marker Ki-67 relative to control and normalized to levels of glyceraldehyde 3-phosphate dehydrogenase mRNA. D: Measurements of crypt length relative to control. Data are shown as the means \pm SEM (B-D). $n=3$ (B-D, control and sham); $n=6$ (B-D, ICR). ${ }^{*} P<0.05$ versus control. Scale bar $=100 \mu \mathrm{m}$.
Archive kit (ABI, Grand Island, NY), and real-time PCR was performed using Power SYBR Green $2 \times$ Master Mix (ABI) on an ABI 7500 Real-Time PCR System. Primers were designed to span genomic DNA intron junctions for specific amplification of mRNA. Samples were normalized to the expression of glyceraldehyde 3-phosphate dehydrogenase. Primer sequences for all transcripts are provided in
Table 2. Fold increases were calculated using the $\Delta \Delta \mathrm{C}_{\mathrm{T}}$ method.

\section{Statistical Analysis}

A two-tailed $t$-test was used to evaluate differences between control and experimental groups. Differences were
A

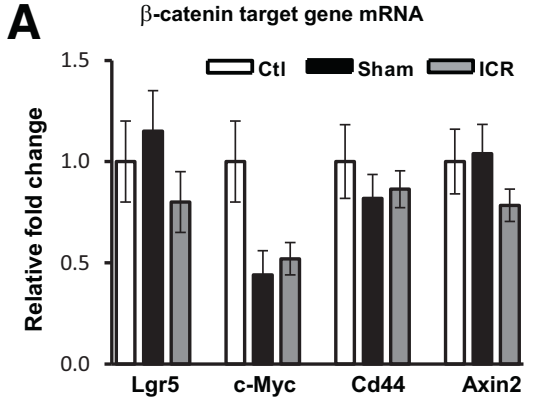

C

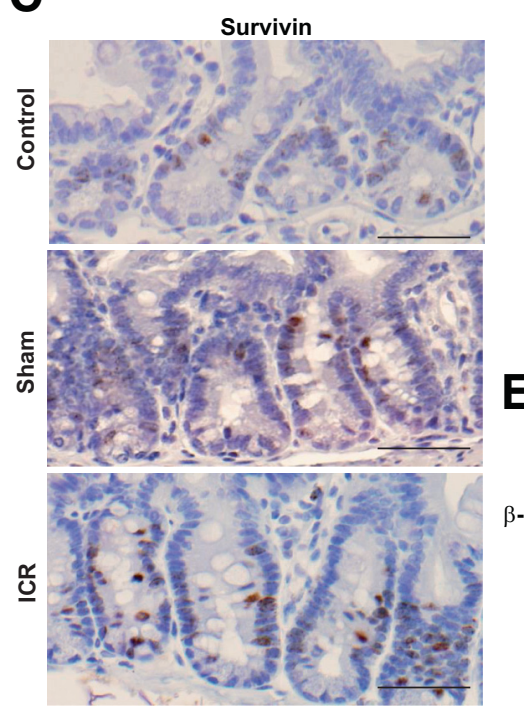

B

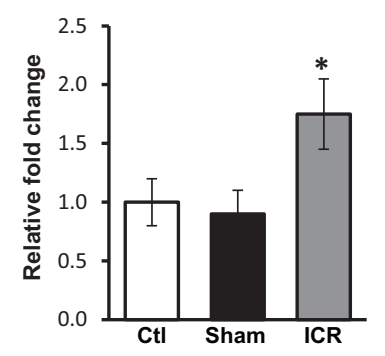

D

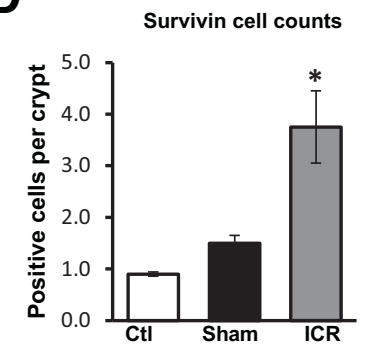

CtI Sham ICR

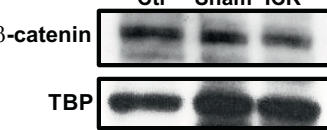

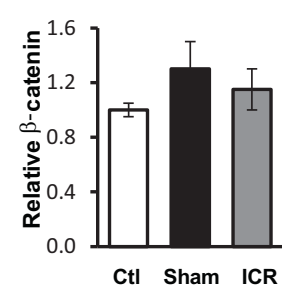

Figure 2 Ileocecal resection (ICR) increases levels of survivin independently of nuclear $\beta$-catenin. Real-time RT-PCR from control (ctl), sham, and ICR mice for Lgr5, c-Myc, Cd44, Axin2 (A) and survivin (B). Results are normalized to levels of glyceraldehyde 3-phosphate dehydrogenase and shown relative to control. C: Representative IHC sections from control, sham, and ICR mice stained for survivin demonstrate increased numbers of survivin-positive intestinal epithelial cell (IEC) after ICR. D: Survivin-positive IECs are represented as the mean number of survivinpositive cells per crypt. E: IECs were isolated from control, sham, and ICR small intestine and nuclear protein fractions were extracted and subjected to Western blot (WB). Representative WB and densitometry for total $\beta$-catenin revealed no significant changes in protein levels. Tata binding protein (TBP) was used as a nuclear fraction loading control. Data are shown as the means \pm SEM (A, B, D, and $\mathbf{E}) . n=4$ (A, ctl and sham) $n=5$ (A, ICR); $n=3$ (C, ctl and sham, and $\mathbf{E}$, ctl, sham, and ICR); $n=6$ (C, ICR). ${ }^{*} P<0.05$ versus control. Scale bars $=50 \mu \mathrm{m}$. 
A

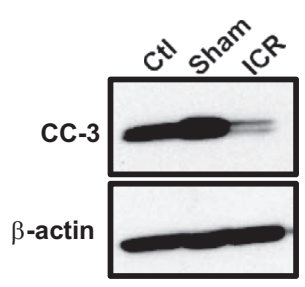

B

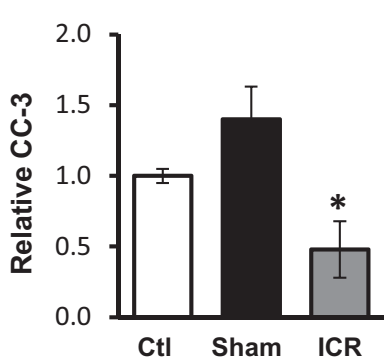

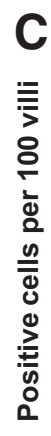

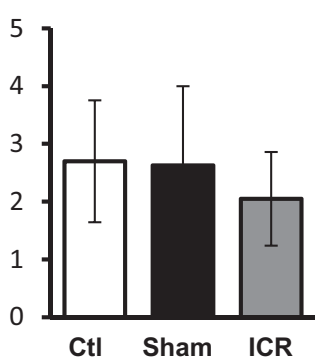

Figure 3 Ileocecal resection (ICR) decreases cleaved caspase-3 protein. A: Representative Western blot for cleaved caspase-3 (CC-3) in cytoplasmic fractions from intestinal epithelial cell (IEC) of control (ctl), sham, and ICR mice. Data show reduced levels of CC-3 in the ICR mice compared with control or sham. B: Densitometry results were normalized to $\beta$-actin and shown relative to control. C: Quantitation of CC-3-positive cells in control, sham, and ICR jejunum. Data are shown as the means \pm SEM (B and C). $n=3$ (B, ctl, sham, and ICR, and C, ctl and sham); $n=6$ (C, ICR). ${ }^{*} P<0.05$ versus control. considered statistically significant when $P<0.05$. Data are presented as the means \pm SEM.

\section{Results}

\section{ICR Increases IEC Proliferation and SB Crypt Length}

To examine IEC adaptation to ICR, intact control mice were compared with mice that underwent bowel transection without resection (sham) and with mice with ICR. IEC proliferation was examined by staining tissue sections for BrdU incorporation. Numbers of BrdU-positive crypt IEC increased by $69 \%$ in ICR mice relative to control, and $41 \%$ relative to sham mice (Figure 1, A and B). This result was supported by real-time RT-PCR for the proliferation marker Ki-67 (Figure 1C). Crypt lengths increased 60\% after ICR relative to controls (Figure 1D). Thus, expansion of the proliferative zone correlated with crypt elongation 5 days after ICR.

\section{Survivin Is Up-Regulated 5 Days after ICR}

Because $\beta$-catenin signaling is important for crypt stem/ progenitor cell proliferation, we examined levels of $\beta$-catenin target gene mRNA in isolated crypt IEC. RNA was extracted from the distal jejunum and assessed by realtime RT-PCR. Data show that ICR failed to significantly alter mRNA levels of the Wnt target genes, Lgr5, c-Myc, Cd44, or Axin2 (Figure 2A). However, survivin mRNA was increased 1.75-fold after ICR $(P<0.05)$ (Figure 2B). IHC staining of tissue sections confirmed that the number of survivin-positive cells was significantly increased after ICR relative to both control and sham mice $(P<0.05)$ (Figure 2, $\mathrm{C}$ and $\mathrm{D})$. To determine whether the increase in survivin expression was because of an increase in nuclear $\beta$-catenin protein or $\beta$-catenin transcriptional activation, IEC nuclear fractions were examined for $\beta$-catenin protein levels. Western blot data indicate that nuclear accumulation of $\beta$-catenin was not increased 5 days after ICR (Figure 2E). These data indicate that increased survivin after ICR does not require augmented $\beta$-catenin signaling.

\section{ICR Decreases Cleaved Caspase-3}

Survivin is known to inhibit caspase-3 activation. ${ }^{16}$ To examine if increased survivin had functional consequences,

\section{A}
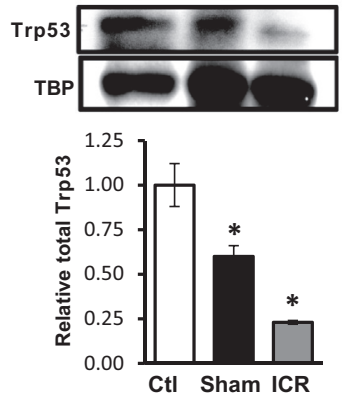

B

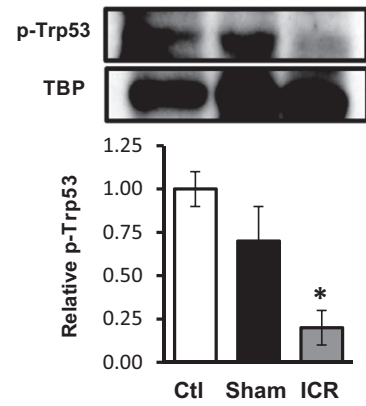

C

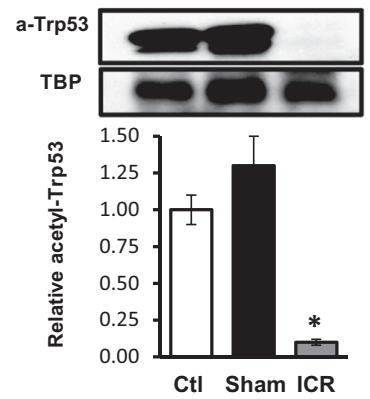

Figure 4 Ileocecal resection (ICR) decreases Trp53 nuclear accumulation and activity. Western blot (WB) analysis and densitometry of intestinal epithelial cell (IEC) nuclear fractions from control (ctl), sham, and ICR mice for total Trp53 (A), p$\operatorname{Trp}^{5} 3^{\text {S9 }}\left(\right.$ B) , and acetyl-Trp53 ${ }^{\mathrm{K} 370}$ (C). TATA binding protein (TBP) was used as a loading control (as in Figure 2E). D: Real-time RT-PCR for the Trp53 targets Dr5 and puma indicate decreased Trp53 activity in ICR compared with control or sham mice. E: WB analysis of IEC cytosolic fractions from control, sham, and ICR mice for (Pik3r1) p85a. Data are shown as the means \pm SEM (A-E). $n=3(\mathbf{A}-\mathbf{C}$ and $\mathbf{E}$, ctl, sham, and ICR; D, ctl and sham); $n=6$ (D, ICR). ${ }^{*} P<0.05$ versus control. 
A

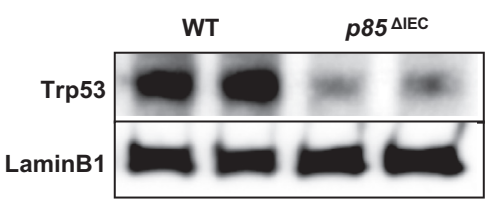

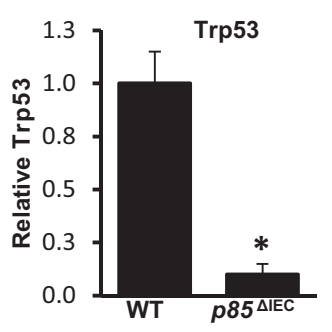

B
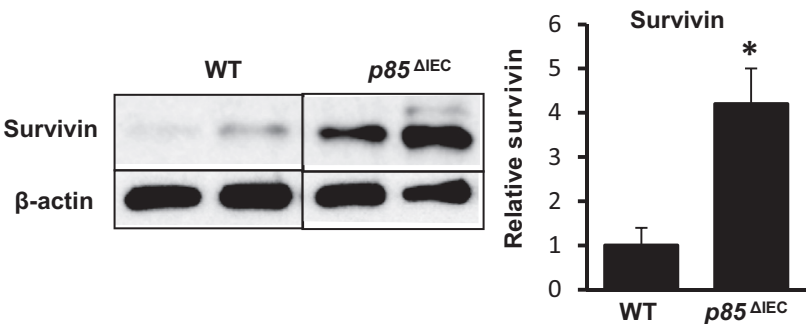

Figure 5 Loss of Pik3r1 (p85 $\alpha$ ) reduces Trp53 and increases survivin expression. A: Representative Western blot (WB) and densitometry of jejunal cytosolic fractions of intestinal epithelial cells (IECs) from wild-type (WT) or $p 85^{\triangle I E C}$ mice for Trp53. B: Representative WB and densitometry of jejunal nuclear fractions of IEC from WT or $p 85^{\Delta I E C}$ for survivin. Data are shown as the means \pm SEM $(\mathbf{A}$ and $\mathbf{B}) . n=4$ (A and $\mathbf{B}$, WT and $\left.p 85^{\Delta I E C}\right)$. ${ }^{\star} P<0.05$ versus WT.

we evaluated cleaved caspase-3 levels in IEC after ICR. Western blots for cleaved caspase-3 (active) were performed on IEC cytosolic lysates from control, sham, and ICR mice (Figure 3, A and B). Analysis revealed a 52\% decrease in cleaved caspase-3 protein levels after ICR compared with control animals. IHC staining for cleaved caspase- 3 did not show evidence of apoptosis in the SB crypts of control, sham, or ICR mice. Rather, apoptotic cells were restricted to villus tip IECs where no differences were detected among groups tested (Figure 3C).

\section{ICR Down-Regulates Trp53 Protein and Activity}

Given that survivin levels were elevated after ICR without an increase in $\beta$-catenin signaling, we examined survivin regulation via transcriptional repression by Trp53. ${ }^{12}$ The level of total nuclear Trp53 reduced by $77 \%$ after ICR (Figure 4A). We analyzed Trp53 activation by measuring two forms of post-translational modification: $\mathrm{p}-\mathrm{Trp} 53^{\mathrm{S} 9}$, which has been shown to play a role in survivin repression; and acetyl$\operatorname{Trp} 53^{\mathrm{K} 370}$, which affects apoptosis by affecting Trp53 transcriptional activity (Figure 4, B and C). Biochemical analyses of nuclear protein fractions indicated that $\mathrm{p}-\mathrm{Trp} 53^{\mathrm{S} 9}$ and acetyl-Trp53 ${ }^{\mathrm{K} 370}$ were significantly reduced after ICR compared with control ( $80 \%$ and $90 \%$ reductions, respectively) or sham-operated on mice ( $71 \%$ and $92 \%$ reductions, respectively). Reduced levels of acetyl-Trp53 ${ }^{\mathrm{K} 370}$ correlated well with reductions in mRNA levels of the Trp53 target genes, Dr5 and puma (Figure 4D). Together, these data support the interpretation that reductions in active Trp53 (specifically
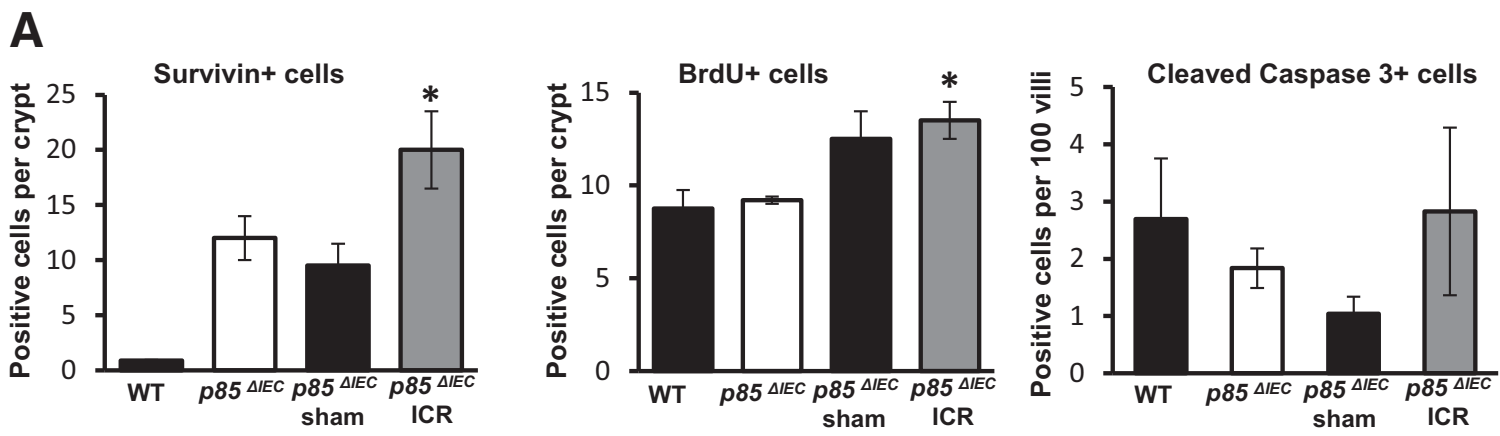

B
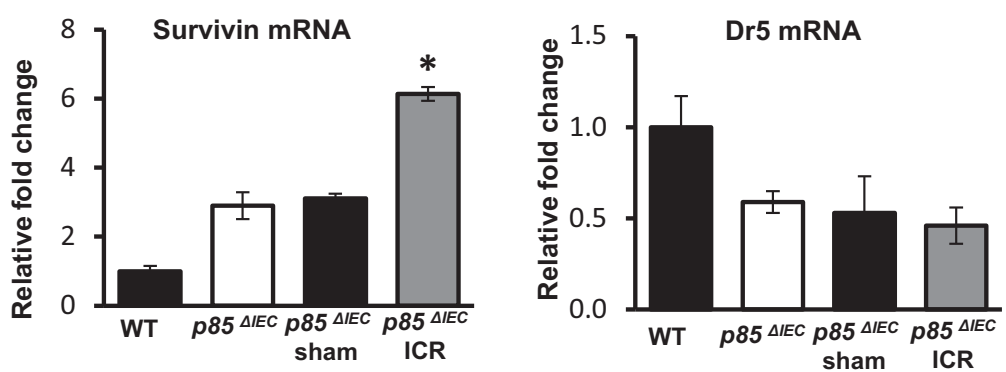

Figure 6 Pik3r1 (p85) regulates survivin expression after ileocecal resection (ICR). A: Quantitation of cells positive for survivin, bromodeoxyuridine (BrdU), and cleaved caspase- 3 in the jejunum of $p 85^{\triangle I E C}$ control, $p 85^{\triangle I E C}$ sham, and $p 85^{\Delta I E C}$ ICR mice. Counts for wild-type (WT) control mice are shown for reference. B and C: Real-time RT-PCR for mRNA expression of survivin and Dr5 in intestinal epithelial cells isolated from jejunum of WT control, $p 85^{\Delta I E C}$ control, $p 85^{\triangle I E C}$ sham, and $p 85^{\triangle I E C}$ ICR mice. Data are shown as the means \pm SEM $(\mathbf{A}-\mathbf{C}) .{ }^{*} P<0.05$ versus $p 85^{\Delta I E C}$. 

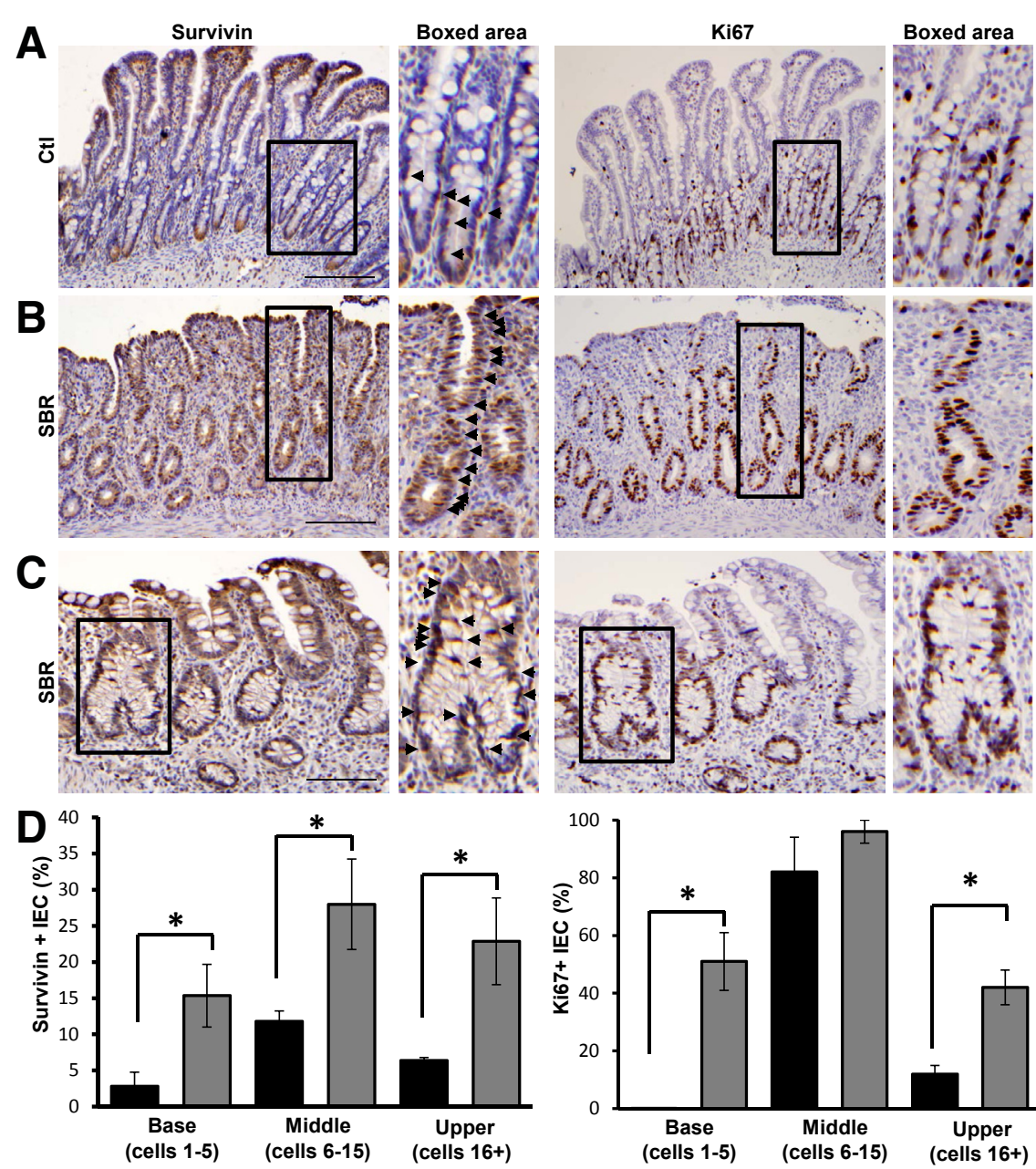

Figure 7 Small-bowel resection (SBR) increases survivin and proliferation in human infants. Representative images of survivin and Ki-67 staining of serial sections from control and resected infant $(<1$ year) human SB. A: Normal ileum [control (ctl)]. B: Ileostomy take down with history of necrotizing enterocolitis (SBR). C: 0stomy repair after spontaneous perforation (SBR). Arrowheads identify survivin-positive cells (A-C). D: Quantification of the percentage of survivin- or Ki-67-positive cells in the crypt base (positions 1 to 5 in the hemicrypt), middle crypt (transit amplifying zone, positions 6 to 15 ), and upper crypt (position $\geq 16$ ) in control (black bars) and post-resection (gray bars) ileum. Boxed areas are shown in higher magnification on the right $(\mathbf{A}-\mathbf{C})$. Data are shown as the means \pm SEM (D). $n=3$ (D, control); $n=6$ (D, post-resection). ${ }^{*} P<0.05$ versus control. Scale bars: $150 \mu \mathrm{m}$ (A and B); $100 \mu \mathrm{m}(\mathbf{C})$. Original magnification: $\times 3.8(\mathbf{A}$, boxed area), $\times 5.2(\mathrm{~B}$, boxed area); $\times 3.5(\mathrm{C}$, boxed area).

acetyl-Trp53 ${ }^{\mathrm{K} 370}$ ) reduced repression on the survivin promoter and increased survivin expression after ICR.

Data herein suggest that reduced Trp53 enhanced survivin levels. Because acetyl-Trp53 ${ }^{\mathrm{K} 370}$ is regulated by the phosphoinositide 3-kinase subunit (Pik3r1) p85 $\alpha$ in stress response models, ${ }^{13}$ we examined $\mathrm{p} 85 \alpha$ protein levels in IEC after ICR. Western blot data showed that after ICR, IEC cytosolic p85 $\alpha$ levels decreased $77 \%$ compared with control mice (Figure 4E). To interrogate the relationship of $\mathrm{p} 85$ to Trp53 and survivin levels at baseline, protein samples from isolated jejunal IEC in WT and epithelial p $85 \alpha$-deficient $\left(p 85^{\Delta I E C}\right.$ ) mice were analyzed. ${ }^{6}$ Western blots revealed that levels of total Trp53 decreased by $90 \%$ in $p 85^{\Delta I E C}$ IEC compared with WT mice (Figure 5A). This correlated well with a 4.2-fold increase in survivin protein levels in $p 85^{\Delta I E C}$ IEC (Figure 5B).

To further clarify the contribution of $\mathrm{p} 85 \alpha$ during ICR, IEC responses were examined in $p 85^{\Delta I E C}$ mice. $^{6}$ At baseline, the number of survivin-positive cells in $p 85^{\triangle I E C}$ mice is 13-fold higher (Figure 6A) and levels of survivin mRNA are 2.9-fold higher than in WT (Figure 6B). Analysis of survivin-stained cells after ICR suggested that $p 85^{\Delta I E C}$ mice had a blunted response to ICR relative to WT (1.6-fold increase versus fourfold increase, respectively). Interestingly, analysis of survivin mRNA levels suggested mRNA responses to ICR were comparable for $p 85^{\Delta I E C}$ and WT mice (twofold increase versus 1.75-fold increase). These latter data are consistent with the conclusion that alternative pathways may be involved.

ICR increased BrdU incorporation in $p 85^{\Delta I E C}$ mice by $30 \%$ (compared with a $69 \%$ induction in WT) but did not significantly alter numbers of apoptotic (cleaved caspase- 3 positive) cells (Figure 6A). Compared with WT, jejunal IEC from $p 85^{\Delta I E C}$ mice exhibited lower levels of the Trp53 target gene $\operatorname{Dr} 5$ at baseline (59\%), and ICR failed to further decrease Dr5 expression (Figure 6C). Thus, the findings of this model support the paradigm that reduced $\mathrm{p} 85 \alpha$ after ICR contributes to lower Trp53 activity and increased survivin after ICR. Thus, regulation of survivin responses to ICR appears to operate via both $\mathrm{p} 85$-dependent and $\mathrm{p} 85$ independent mechanisms.

SBR Reduces TP53 and Increases Survivin Levels in the Crypt TA Zones of Infant Patients

Given the effect of ICR on epithelial survivin in mice, we next examined SB from infants after SBR. Ileal tissue from control and post-resection infants was stained for survivin, 
Ki-67, and TP53. All patients were $<1$ year of age, with SBR performed primarily for NEC or spontaneous perforation (Table 1). In sections from control patients, survivin-positive cells predominated in proliferative TA zones but were relatively sparse in crypt bases (Figure 7A). Comparisons of SBR tissue revealed that resection increased survivin-positive TA cells by $57 \%(P<0.05)$ (Figure 7D). Although survivin and Ki-67 were generally not detected on villi, a subset of patients exhibited relatively high levels of both markers near the surface (Figure 7B). In addition, mitotic cells within areas of active crypt remodeling, characterized by crypt fissioning and architectural distortion, stained positively for survivin (Figure 7C). Although impressive changes occurred in the TA zone of resected infants, the effects of survivin extended to crypt bases and the upper crypt as well. Resection induced survivin fivefold and threefold in crypt bases and upper crypts, respectively (Figure 7D). Analogous effects were seen for Ki-67 (Figure 7D). In contrast, SBR decreased numbers of TP53-positive IEC in the base and TA zones (Figure 8). Together, these findings suggest that intestinal resection reduces TP53, which subsequently increases survivin and IEC proliferation. These data are in good agreement with conclusions in our own murine model that places regulation of survivin as a key step in intestinal adaptation to resection.

\section{Discussion}

The findings of this study identify survivin regulation in proliferative TA zones as a key factor in increasing SB surface area after ICR, via expansion of the crypt/villus axes. This is consistent with the reported roles of survivin in both increasing cell cycle progression and decreasing apoptosis. Studies with Teduglutide, synthetic glucagon-like peptide 2, indicate that increased crypt elongation and villus height correlate with improved clinical outcomes (reduced parenteral fluid requirements). ${ }^{17}$ The expansion of absorptive surface likely occurs because of several mechanisms. Data from Dekaney et $\mathrm{al}^{7}$ indicate that fissioning-mediated expansion of the crypt units is likely related to intestinal stem cell activation. In addition, TA zone expansion relies on increased proliferation and reduced apoptosis. In mouse studies, we found that immediately after ICR, reduced Trp53 acetylation released repression of survivin transcription. The increase in survivin correlated well with reduced caspase-3 activation. Although histological evidence of apoptosis after ICR was not detected, reduced protein levels of cleaved caspase-3 would facilitate expansion of proliferating progenitor cells, resulting in adaptive expansion of the SB surface area. We propose that increasing survivin levels is a desirable end point of agents such as glucagon-like peptide 2 , which endeavor to promote enteral autonomy.

Multiple cancers, including breast, gastric, colorectal, prostate, and thyroid, have demonstrated an increase in
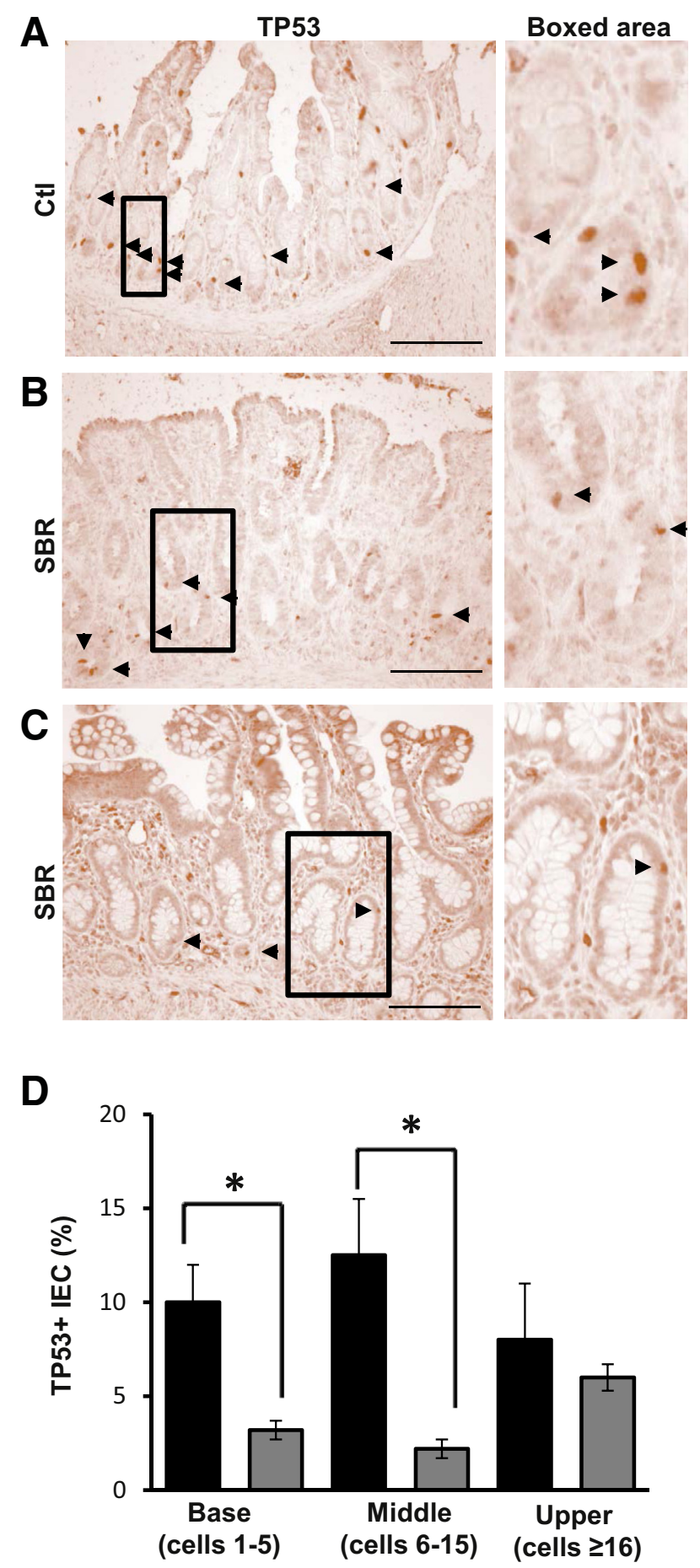

Figure 8 Small-bowel resection (SBR) decreases TP53 in human infants. Representative images of TP53 staining from control and resected infant $(<1$ year) human SB. A: Normal ileum [control (ctl)]. B: Ileostomy take down with history of necrotizing enterocolitis (SBR). C: Ostomy repair after spontaneous perforation (SBR). Arrowheads identify TP53-positive intestinal epithelial cell (IEC) (A-C). Boxed areas are shown in higher magnification on the right (A-C). D: Quantification of the percentage of TP53-positive cells in the crypt base (positions 1 to 5 in the hemicrypt), middle crypt (transit amplifying zone, positions 6 to 15), and upper crypt (position $\geq 16$ ) in control (black bars) and post-resection (gray bars) ileum. Data are shown as the means \pm SEM (D). $n=3$ (D, control); $n=6$ (D, post-resection). ${ }^{*} P<0.05$ versus control. Scale bar $=100 \mu \mathrm{m}(\mathbf{A}-\mathbf{C})$. Original magnification: $\times 9.2(\mathbf{A}$, boxed area) $\times 5.0(B$, boxed area $) ; \times 4.0(C$, boxed area) 
survivin. ${ }^{9}$ In colorectal cancer and breast cancer, survivin expression has been shown to be an indicator of poor outcome and suboptimal response to therapy. In addition, enhanced survivin in the lamina propria of Crohn's disease tissue was linked to increased survival of mucosal $\mathrm{T}$ lymphocytes. ${ }^{18}$ Interestingly, de Souza et $\mathrm{al}^{18}$ reported that epithelial survivin is reduced in inflammatory bowel disease compared with normal. These findings are consistent with previous results from our laboratory showing that IEC TP53 levels and apoptosis increase in inflammatory bowel disease. ${ }^{19}$ Thus, the mechanisms observed herein may operate to reduce IEC apoptosis after ICR and increase IEC apoptosis in inflammatory bowel disease. Published data also suggest that survivin may regulate proliferation directly, through regulation of cell cycle at the $\mathrm{G}_{2} / \mathrm{M}$ phase. ${ }^{9,20}$ To our knowledge, the studies herein represent the first interrogation of the role of survivin in the expansion of crypt IEC during nonmalignant responses.

Comparisons among different murine models used to model human SBR suggest that differences in IEC apoptosis may relate to the amount of bowel resected. Regulating apoptosis may be an important means for enhancing the adaptive response in clinical settings, such as short bowel syndrome. Previous publications report that IEC cleaved caspase-3 activation increases in mice after massive $(>50 \%) \mathrm{SBR}^{21}$ In data presented in the current model (approximately 30\% resection), we found reduced levels of activated caspase-3 (Figure 3). An explanation for these differences may relate to the relative changes in survivin in these two systems. We found IEC survivin increased after 30\% ICR (Figure 2), yet we failed to detect significant changes in survivin mRNA levels in the jejunum or ileum of WT mice after 50\% resection (data not shown). Differences in the length of resected SB may also explain why we failed to detect changes in intestinal stem cell activation (Figure 2E), as reported by others after more extensive resection. These data suggest that multiple signaling pathways and regulatory mechanisms related to the degree of bowel resected may be involved in adaptive responses to SBR.

Our goal was to interrogate mechanisms of intestinal adaptation relevant to human infants. Data generated from surgical records of our SBR patients indicated that the length of resection ranged from 2 to $10 \mathrm{~cm}$ (Table 1). Given that the median SB length in newborns is 200 to $300 \mathrm{~cm},{ }^{22}$ these resections reflect a relatively small percentage of the total SB. Therefore, the human data shown herein may be more reflective of mechanisms operating in murine models of $30 \%$ ICR compared with 50\% ICR. Thus, we propose that data in the murine ICR model shown herein bear clinical relevance to conditions encountered by clinicians caring for this critically ill group of patients.

After surgical resection of SB, patients must respond to the challenge of being left with suboptimal intestinal surface area. The current study interrogates this adaptive response and found significant increases in survivin levels in IECs from ICR mice in a mechanism distinct from $\beta$-catenin signaling. Because survivin activity is repressed by $\operatorname{Trp} 53$, reductions in Trp53 and p85 $\alpha$ protein levels in IEC are one mechanism by which survivin mRNA expression and protein levels are enhanced by ICR. These findings led us to conclude that ICR-induced reductions in $\mathrm{p} 85 \alpha$ and active TP53 lead to increased survivin activity and enhanced crypt IEC survival and expansion.

\section{Acknowledgment}

We thank Lewis Cantley (Weill Cornell Medical College) for providing the $p i k 3 r 1^{f l f l}$ mice.

\section{References}

1. Hess RA, Welch KB, Brown PI, Teitelbaum DH: Survival outcomes of pediatric intestinal failure patients: analysis of factors contributing to improved survival over the past two decades. J Surg Res 2011, 170: $27-31$

2. Vanderhoof JA, Langnas AN: Short-bowel syndrome in children and adults. Gastroenterology 1997, 113:1767-1778

3. Sondheimer JM, Cadnapaphornchai M, Sontag M, Zerbe GO: Predicting the duration of dependence on parenteral nutrition after neonatal intestinal resection. J Pediatr 1998, 132:80-84

4. Spencer AU, Kovacevich D, McKinney-Barnett M, Hair D, Canham J, Maksym C, Teitelbaum DH: Pediatric short-bowel syndrome: the cost of comprehensive care. Am J Clin Nutr 2008, $88: 1552-1559$

5. Scoville DH, Sato T, He XC, Li L: Current view: intestinal stem cells and signaling. Gastroenterology 2008, 134:849-864

6. Lee G, Goretsky T, Managlia E, Dirisina R, Singh AP, Brown JB, May R, Yang GY, Ragheb JW, Evers BM, Weber CR, Turner JR, He XC, Katzman RB, Li L, Barrett TA: Phosphoinositide 3-kinase signaling mediates beta-catenin activation in intestinal epithelial stem and progenitor cells in colitis. Gastroenterology 2010, 139:869-881. 881.e1-881.e9

7. Dekaney CM, Fong JJ, Rigby RJ, Lund PK, Henning SJ, Helmrath MA: Expansion of intestinal stem cells associated with longterm adaptation following ileocecal resection in mice. Am J Physiol Gastrointest Liver Physiol 2007, 293:G1013-G1022

8. Helmrath MA, Erwin CR, Warner BW: A defective EGF-receptor in waved-2 mice attenuates intestinal adaptation. J Surg Res 1997, 69: $76-80$

9. Church DN, Talbot DC: Survivin in solid tumors: rationale for development of inhibitors. Curr Oncol Rep 2012, 14:120-128

10. Raj D, Liu T, Samadashwily G, Li F, Grossman D: Survivin repression by $\mathrm{p} 53, \mathrm{Rb}$ and E2F2 in normal human melanocytes. Carcinogenesis 2008, 29:194-201

11. Gudkov AV, Komarova EA: Pathologies associated with the p53 response. Cold Spring Harb Perspect Biol 2010, 2:a001180

12. Hoffman WH, Biade S, Zilfou JT, Chen J, Murphy M: Transcriptional repression of the anti-apoptotic survivin gene by wild type p53. J Biol Chem 2002, 277:3247-3257

13. Song L, Gao M, Dong W, Hu M, Li J, Shi X, Hao Y, Li Y, Huang C: p85alpha mediates p53 K370 acetylation by p300 and regulates its promoter-specific transactivity in the cellular UVB response. Oncogene 2011, 30:1360-1371

14. Arai S, Matsushita A, Du K, Yagi K, Okazaki Y, Kurokawa R: Novel homeodomain-interacting protein kinase family member, HIPK4, 
phosphorylates human p53 at serine 9. FEBS Lett 2007, 581: 5649-5657

15. Crosnier C, Stamataki D, Lewis J: Organizing cell renewal in the intestine: stem cells, signals and combinatorial control. Nat Rev Genet 2006, 7:349-359

16. Shin S, Sung BJ, Cho YS, Kim HJ, Ha NC, Hwang JI, Chung CW, Jung YK, Oh BH: An anti-apoptotic protein human survivin is a direct inhibitor of caspase-3 and -7. Biochemistry 2001, 40: $1117-1123$

17. Tappenden KA, Edelman J, Joelsson B: Teduglutide enhances structural adaptation of the small intestinal mucosa in patients with short bowel syndrome. J Clin Gastroenterol 2013, 47: 602-607

18. de Souza HS, West GA, Rebert N, de la Motte C, Drazba J, Fiocchi C: Increased levels of survivin, via association with heat shock protein 90 in mucosal T cells from patients with Crohn's disease. Gastroenterology 2012, 143:1017-1026.e9

19. Goretsky T, Dirisina R, Sinh P, Mittal N, Managlia E, Williams DB, Posca D, Ryu H, Katzman RB, Barrett TA: p53 mediates TNFinduced epithelial cell apoptosis in IBD. Am J Pathol 2012, 181: $1306-1315$

20. Li F, Ambrosini G, Chu EY, Plescia J, Tognin S, Marchisio PC, Altieri DC: Control of apoptosis and mitotic spindle checkpoint by survivin. Nature 1998, 396:580-584

21. Shin CE, Falcone RA Jr, Kemp CJ, Erwin CR, Litvak DA, Evers BM, Warner BW: Intestinal adaptation and enterocyte apoptosis following small bowel resection is p53 independent. Am J Physiol 1999, 277: G717-G724

22. Hwang ST, Shulman RJ: Update on management and treatment of short gut. Clin Perinatol 2002, 29:181-194. vii 